\title{
Analysis of Ground Potential Rise with Lightning Stroke to Lightning Rods on Frame inside Substation
}

\author{
Songping Tang ${ }^{1}$, Xiaobin $\mathrm{Wu}^{2}$ \\ Huizhou Power Supply Bureau of Guangdong Power Grid Corporation Huizhou, China \\ tangsongping@gmail.com ${ }^{1}$, 15819889275@139.com ${ }^{2}$
}

of the substation by means of numerical method, also

Abstract-The grounding system is an important part for substation lightning protection. As the lightning rods of the large substation are in multi-point connection with the grounding grid through the frame, the distribution of ground potential along the grounding grid is different from that around the independent lightning rod. The paper sets up the overall model on the lightning rods, the frame, and the grounding grid. Then, the transient characteristics of the substation grounding grid at $1 \mathrm{~A}$ lightning current of 2.6/50 $\mu \mathrm{s}$ when the lightning rods on the frame are struck are calculated. The impulse grounding resistance and the ground potential distribution of the grounding grid with different grounding parameters are discussed. The results will be a good reference for the design of the grounding device of the lightning rods on the frame.

Keywords-substation; lightning stoke; grounding grid; ground potential rise; impulse grounding resistance

\section{FOREWORD}

The grounding system is an important part for substation lightning protection [1]. As the lightning current has higher amplitude value and rich frequency content generally and is different from the general power frequency current, if the effect on grounding grid potential distribution after lightning current enters the grounding grid needs to be analyzed, the transient characteristics of the grounding grid must be considered [2-4]. A lot of study works has been developed on the transient characteristics of the grounding grid at home and aboard. The substation with low voltage level generally uses the independent lightning rods for lightning protection; and as the substation with high voltage level has higher insulation capacity, the lightning rods are allowed to be arranged on the frame, thereby being in multi-point connection with the grounding grid through the frame and forming a closer link with other grounding grids. At the moment, the lightning rods, the lightning rod frame, the grounding grid and the soil form a whole body, and the lightning current diffuses into ground through a plurality of frame ground points. The existing reference has analyzed the lightning current or the characteristics of the grounding grid independently in stead of the processes of transmitting and diffusing the lightning current through the frame, thereby being not enough to explain the actual lightning situation [2-4].

The paper carries out overall modeling on the lightning rods, the frame, the grounding grid and the like carries out simulation calculation on the transient characteristics of the substation grounding grid at $1 \mathrm{~A}$ lightning current of $2.6 / 50 \mu$ s when the lightning rods on the frame are struck by lightning and analyzes the impulse grounding resistance of the grounding grid and the ground potential distribution under different grounding parameters when lightning stoke is encountered. A reference is provided for design of the grounding mode of the lightning rods on the frame.

\section{ANALYSIS ON MAIN FACTORS AFFECTING DISTRIBUTION OF POTENTIAL INSIDE SUBSTATION UNDER LIGHTNING STROKE AND DEFINITION OF CALCULATED PARAMETERS}

Lightning stroke position, grounding conductor materials, grounding grid area, soil resistivity, grounding conductor radius, grounding grid conductor density, frame ground point number and the like can affect the performance of the whole lightning protection and grounding system containing the lightning rods, the frame, the grounding grid and the soil, thereby affecting the distribution of potential inside the substation after the lightning rods are struck by lightning. The paper mainly analyzes the effect on the distribution of potential inside the substation after the above parameters change.

As workers cannot come to the vicinity of the frame for the purpose of safety when thunder and lightning is coming soon, it is not necessary to analyze the stride contact potential. Instead, the potential difference inside the substation caused by lightning current diffusing into ground may threaten equipment and personnel safety, so the paper mainly analyzes the distribution of maximum potential difference. In addition, as the impulse grounding resistance is one of more important parameters, it is given in the paper during analysis and calculation. The above parameters are defined as follows:

1. As for the distribution of potential difference inside the substation, firstly dividing the grounding grid into two areas: an area within $10 \mathrm{~m}$ away from the peripheries of the door-shaped frame's ground points and a remaining grounding grid area which are respectively called an inside area and an outside area for short and displaying the maximum peak potential difference of the inside area, the maximum peak potential difference of the outside area and the maximum peak potential difference of the whole grounding grid in the calculated results

2. Due to the existence of the frame, it is not enough that only the grounding resistance of the grounding grid is 
simply considered. Therefore, the paper defines the impulse grounding resistance as a ratio of a potential rise peak value at the main current diffusing into ground (i.e. the frame ground point that is closest to the lightning stroke position) to a lightning current peak value.

\section{EFFECT OF LIGHTNING STROKE POSITION ON DISTRIBUTION OF POTENTIAL INSIDE SUBSTATION}

The grounding grid has an area of $200 \times 200 \mathrm{~m} 2$ and a burial depth of $0.8 \mathrm{~m}$. The frame has a height of $25 \mathrm{~m}$ and is provided with three bases connected with the grounding grid; and three lightning rods are arranged at the top end of the door-shaped frame. The conductor used in the grounding grid and the soil resistivity are shown in Table $\mathrm{I}$, the arrangement of the grounding grid and the frame conductor is shown in Fig. 1, three ground points connected with the grounding grid are formed on the door-shaped frame, and the lightning rods are mounted at the top ends of the frame above all the three ground points. According to the regulations, the grid conductor is encrypted at each frame ground point to conveniently diffuse the lightning current into ground.

TABLE 1 CONDUCTOR AND SOIL RESISTIVITY

\begin{tabular}{|c|c|c|c|}
\hline $\begin{array}{c}\text { Conductor } \\
\text { material }\end{array}$ & $\begin{array}{c}\text { Relative } \\
\text { resistivity } \\
\text { (Relative to } \\
\text { copper) }\end{array}$ & $\begin{array}{c}\text { Relative Magnetic } \\
\text { conductivity } \\
\text { (Relative to } \\
\text { copper) }\end{array}$ & $\begin{array}{c}\text { Soil } \\
\text { resistivity }\end{array}$ \\
\hline Steel & 10 & 636 & $500 \Omega \cdot \mathrm{m}$ \\
\hline
\end{tabular}

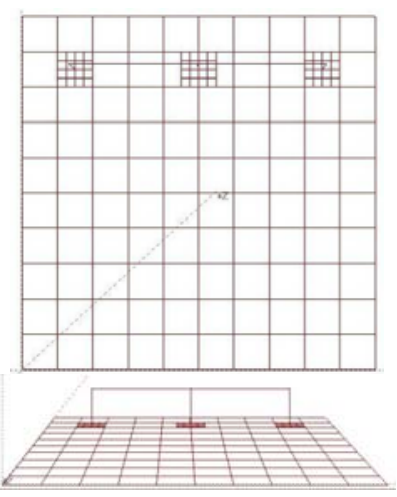

(a) Top View

(b) Front View

Figure 1 Arrangement of Grid Conductor

When the lightning current with an amplitude value of $1 \mathrm{~A}$ is injected from the leftmost side of the top end, the middle part and the rightmost side of the door-shaped frame, the stimulation calculation is carried out on the potential distribution characteristics of the grounding grid are respectively. The simulation results are shown in Table II.

The calculated results show that when the lightning current is injected on the lightning rod in the middle of the frame, all parameters must be smaller than those when the lightning current is injected on the lightning rods on the two sides. Obviously, this is because that when the lightning current is injected on the lightning rod in the middle, the shunt path is smoother, the lightning current better diffuses, and the potential distribution of the grid conductor is more uniform. Therefore, the grounding grid nearby the ground points on the two sides of the frame should be encrypted.

TABLE 2 GROUNDING GRID POTENTIAL DISTRIBUTION UNDER DIFFERENT LIGHTNING STROKE POSITIONS

\begin{tabular}{|c|c|c|c|}
\hline $\begin{array}{l}\text { Lightning current injection } \\
\text { positions }\end{array}$ & Left & Middle & Right \\
\hline $\begin{array}{l}\text { Maximum potential rise of } \\
\text { grounding grid/V }\end{array}$ & 2.928 & 1.971 & 2.928 \\
\hline $\begin{array}{l}\text { Maximum potential difference } \\
\text { of area inside/V }\end{array}$ & 1.218 & 0.772 & 1.218 \\
\hline $\begin{array}{l}\text { Maximum potential difference } \\
\text { of area outside/V }\end{array}$ & 0.784 & 0.389 & 0.784 \\
\hline $\begin{array}{l}\text { Maximum potential difference } \\
\text { in the grid/V }\end{array}$ & 1.538 & 0.807 & 1.538 \\
\hline Impulse grounding resistance $/ \Omega$ & 2.928 & 1.971 & 2.928 \\
\hline
\end{tabular}

The calculated results show that when the lightning current is injected on the lightning rod in the middle of the frame, all parameters must be smaller than those when the lightning current is injected on the lightning rods on the two sides. Obviously, this is because that when the lightning current is injected on the lightning rod in the middle, the shunt path is smoother, the lightning current better diffuses, and the potential distribution of the grid conductor is more uniform. Therefore, the grounding grid nearby the ground points on the two sides of the frame should be encrypted.

\section{EFFECT OF GROUNDING GRID ON DISTRIBUTION OF POTENTIAL INSIDE SUBSTATION}

\section{A. Effect of grounding grid materials on distribution of potential inside substation}

In order to meet the requirements for mechanical strength, the lightning rods and the frame are made of steel generally. However, the grounding grid can be selectively made of different materials. The paper analyzes the distribution of the potential inside the substation when the conductor used in the grounding grid is made of different materials.

The conductor is made of copper and steel respectively and is shown in Table III. The lightning current is injected at the lightning rod on the left side, and other parameters refer to the Section III. The calculated results are shown in Table IV.

TABLE 3 GROUNDING CONDUCTOR

\begin{tabular}{|c|c|c|c|}
\hline Materials & $\begin{array}{c}\text { Radius/m } \\
\text { m }\end{array}$ & $\begin{array}{c}\text { Relative } \\
\text { Resistivity }\end{array}$ & $\begin{array}{c}\text { Relative Magnetic } \\
\text { Conductivity }\end{array}$ \\
\hline Steel & 10 & 10 & 636 \\
\hline Copper & 10 & 1 & 1 \\
\hline
\end{tabular}


TABLE 4 POTENTIAL DISTRIBUTION OF GROUNDING GRID CONDUCTOR MADE OF DIFFERENT MATERIALS

\begin{tabular}{|c|c|c|}
\hline Conductor material & Middle & Right \\
\hline Maximum potential rise of grounding grid/V & 2.928 & 2.894 \\
\hline Maximum potential difference of area inside/V & 1.218 & 1.188 \\
\hline Maximum potential difference of area outside/V & 0.784 & 0.763 \\
\hline Maximum potential difference in the grid/V & 1.538 & 1.469 \\
\hline Impulse grounding resistance/ $\Omega$ & 2.928 & 2.894 \\
\hline
\end{tabular}

The calculated results show that there is a tiny difference between calculated results of two kinds of materials; and when the conductor is made of copper, all parameters must be slightly smaller than those when the conductor is made of steel. Obviously, the copper can balance the grounding grid potential distribution, and its advantages are not obvious compared with those of the copper under the condition of lightning stroke.

\section{B. Effect of grounding grid conductor density on distribution of potential inside substation}

The grounding grid conductor nearby the ground points of the lightning rods on the frame is encrypted generally to conveniently bleed the lightning current. The paper analyzes the effect of different densities of centralized grounding devices on the distribution of the potential inside the substation, and each centralized grounding device has a total area of $20 \times 20 \mathrm{~m} 2$; the lightning current is injected at the lightning rod on the left side, and other parameters refer to the Section III. The calculated results are shown in Table V.

TABLE 5 POTENTIAL DISTRIBUTION UNDER DIFFERENT CONDUCTOR DENSITIES

\begin{tabular}{|c|c|c|}
\hline Grid conductor spacing/m & 2.5 & 5 \\
\hline Maximum potential rise of grounding grid/V & 2.795 & 2.928 \\
\hline Maximum potential difference of area inside/V & 1.089 & 1.218 \\
\hline Maximum potential difference of area outside/V & 0.794 & 0.784 \\
\hline Maximum potential difference in the grid/V & 1.499 & 1.538 \\
\hline Impulse grounding resistance/ $\mathbf{\Omega}$ & 2.795 & 2.928 \\
\hline
\end{tabular}

The calculated results show that along with the increase of conductor density, all parameters (excluding the maximum potential difference of the outside area) basically trend to decrease. Obviously, through the increase of the conductor density, the potential distribution of the inside area is balanced, the potential difference of the inside area is reduced, and meanwhile, and the maximum potential rise of the whole grounding grid is also reduced; and although the potential difference of the inside area increases, its amplitude of variation is smaller and can be within an error range.

\section{EFFECT OF SOIL RESISTIVITY ON DISTRIBUTION OF POTENTIAL INSIDE SUBSTATION}

The soil resistivity directly affects the proportion of lightning current diffusing into ground when it flows in the conductor, and different soil resistivity will generate different effects. The paper analyzes the distribution of potential inside the substation when the soil resistivity takes $100,500,1000$ and $2000 \Omega \cdot \mathrm{m}$ respectively, the lightning current is injected at the lightning rod on the left side, and other parameters refer to the Section 3. The calculated results are shown in Table VI.

TABLE 6 POTENTIAL DISTRIBUTION OF GROUNDING GRID CONDUCTOR MADE OF DIFFERENT MATERIALS

\begin{tabular}{|c|c|c|c|c|}
\hline 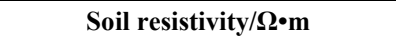 & 100 & 500 & 1000 & 2000 \\
\hline $\begin{array}{l}\text { Maximum potential rise of } \\
\text { grounding grid/V }\end{array}$ & 1.234 & 2.928 & 4.088 & 5.584 \\
\hline $\begin{array}{c}\text { Maximum potential difference of } \\
\text { area inside/V }\end{array}$ & 0.537 & 1.218 & 1.672 & 2.258 \\
\hline $\begin{array}{c}\text { Maximum potential difference of } \\
\text { area outside } / V\end{array}$ & 0.353 & 0.784 & 0.991 & 1.238 \\
\hline $\begin{array}{l}\text { Maximum potential difference in } \\
\text { the grid/V }\end{array}$ & 0.702 & 1.538 & 2.022 & 2.755 \\
\hline Impulse grounding resistance/ $\Omega$ & 1.234 & 2.928 & 4.088 & 5.584 \\
\hline
\end{tabular}

The calculated results show that along with the increase of soil density, all parameters gradually increase. The increase of soil resistivity directly results in the increase of impulse grounding resistance and maximum potential rise of the grounding grid; and meanwhile, due to larger cardinal number of potential rise, the potential difference of the inside area increases under the same rate of decrease, and further, the maximum potential differences of the outside area and the whole grounding grid increase.

\section{EFFECT OF FRAME GROUND POINT NUMBER ON POTENTIAL DISTRIBUTION}

The door-shaped frame in the substation is provided with a plurality of bases generally, each base corresponds to one ground point connected with the grounding grid, and the lightning current diffuses into ground through these ground points. Obviously, the number of the ground points affects the distribution of lightning current to a great extent and further affects the distribution of potential inside the substation. The paper analyzes the distribution of potential inside the substation when the frame is provided with 2,3 and 4 bases respectively, the lightning current is injected at the lightning rod on the left side, and other parameters refer to the Section III. The calculated results are shown in Table VII.

The calculated results show that along with the increase of the number of bases on the frame, all parameters gradually decrease. As the increase of the number of grounding points provides more shunt paths for lightning current, the total quantity of lightning current diffusing into ground from the ground point closest to the injection position is reduced, so that the maximum 
potential difference of the area inside is reduced, and the substation inside potential distribution is blanched.

TABLE 7 POTENTIAL DISTRIBUTION OF GROUNDING GRID CONDUCTOR MADE OF DIFFERENT MATERIALS

\begin{tabular}{|c|c|c|c|}
\hline Number of ground points & 2 & 3 & 4 \\
\hline $\begin{array}{c}\text { Maximum potential rise of grounding } \\
\text { grid/V }\end{array}$ & 3.145 & 2.928 & 2.631 \\
\hline $\begin{array}{c}\text { Maximum potential difference of area } \\
\text { inside/V }\end{array}$ & 1.441 & 1.218 & 1.126 \\
\hline $\begin{array}{c}\text { Maximum potential difference of area } \\
\text { outside/V }\end{array}$ & 1.056 & 0.784 & 0.693 \\
\hline $\begin{array}{c}\text { Maximum potential difference in the } \\
\text { grid/V }\end{array}$ & 2.006 & 1.538 & 1.427 \\
\hline Impulse grounding resistance/ $\mathbf{\Omega}$ & 2.687 & 2.928 & 2.631 \\
\hline
\end{tabular}

\section{CONCLUSIONS}

The paper carries out simulation calculation on impulse grounding resistance, potential distribution situation and factors affecting the potential distribution when the lightning rod is struck by lightning, thereby obtaining the following results:

1. When the lightning current is injected at the lightning rod in the middle of the frame, all parameters must be smaller than those when the lightning current is injected at the lightning rods on the two sides. Therefore, the grounding grid nearby the ground points on the two sides of the frame should be encrypted.

2. Through encrypting the grounding bodies nearby the frame ground points, the potential distribution of the inside area can be balanced, so that the potential difference of the inside area is reduced, and meanwhile, the maximum potential rise of the whole grounding grid is also reduced.

3. Through increasing the number of the frame ground points, the maximum potential rise inside the substation can be reduced, and the distribution of potential inside the substation can be balanced.

\section{REFERENCES}

[1] IEEE Guide for Safety of AC Substation Groundings, IEEE Std. 80-2000, Jan. 2000

[2] L. Grcev, "Lightning Surge Efficiency of Grounding Grids", IEEE Trans. Power Delivery, vol. 26, pp. 1692-1699, Jul. 2011.

[3] A. P. Meliopoulos, M. G. Moharam, "Transient Analysis of Grounding Systems", IEEE Trans. Power App. Syst., vol. PAS-102, pp. 389-397, Feb. 1983.

[4] M. M. Babu Narayanan, S. Parameswaran, D. Mukhedkar, "Transient Performance of Grounding Grids", IEEE Trans. Power Delivery, vol. 4, pp. 2053-2059, Oct. 1989. 